\title{
Guest Editorial \\ Special Issue on Multilevel Power Converters for Utility Applications
}

Recently, the electric utility industry has been undergoing a revolutionary restructuring process. Conventionally, electric power has been generated by many large power plants and then transmitted and distributed to customers. Most of these power plants are operated based on fossil fuel or nuclear reactors. Due to an increasing concern for environmental issues, renewable energy sources such as wind, photovoltaic, tidal, etc., are now being widely utilized. The capacity of power plants based on renewable energy sources can exceed $1 \mathrm{GW}$ in the case of wind farms consisting of several hundreds of multi MW wind turbines. Even the capacity of photovoltaic generation plants is presently over a MW.

Most renewable energy sources are inherently variable and uncontrollable. And, the frequency and power of electricity generated from renewable energy sources are variable and uncontrollable. To connect this electricity to conventional utility grids, whose frequency and voltage are constant, power converters based on power electronics technology are used in most cases. Due to the switching nature of power converters using power semiconductor devices, the converters inevitably incur problems such as switching noises and harmonics in the grid. As the power ratings of these converters become higher, the noises and harmonics cannot be tolerated in utility grids. To lessen these problems and to accommodate MWs of power in a single converter unit, several multilevel inverter topologies have been introduced and implemented for use in utility interface applications. From the 40 year old Neutral Pointed Clamped (NPC) to the 10 year old Modular Multi-level Converter (MMC), different types of power converter topologies have been applied as utility grid interfaces. However, multilevel converter topologies and their control methods are still evolving. In this context, the papers published in this special issue on Multilevel Power Converters for Utility Applications cover several new topologies and control strategies for existing topologies such as the NPC and MMC. The topologies proposed in this issue seem to be promising for not only as utility grid interfaces and in but also industrial applications for driving large size motors. In addition, the control methods proposed in this special issue are very practical and have been verified by experimental tests. Thus, the papers in this special issue should be helpful to readers interested in multi-level topologies and their control and to general power electronics engineers working in the field to understand the latest trends in power converters.

In this special issue, only 13 papers, from the 123 papers submitted from 19 countries, have been selected for publication. The members of the Editorial Board regret that more papers cannot be published in this special issue due to space limitations. However, some of the papers not published in this special issue may appear in future issues of this journal. The Editorial Board would like to express its special appreciation for the contributions of the reviewers who dedicated their time to reviewing the submitted papers. In addition, the Editorial Board would like to thank Associate Editors, Prof. Jun-Keun Ji (Soonchunhyang University, Asan, Korea), Prof. Kyo-Beum Lee (Ajou University, Suwon, Korea), and Prof. Rae-Young Kim (Hanyang University, Seoul, Korea), who helped manage the reviews for this special issue. Finally, it is hoped that this special issue will serve as a reference for continuing state-of-the-art research in the area of multilevel power converters for use in utility applications.

\section{FANG ZHENG PENG, Guest Editor}

Michigan State University

Department of Electrical and Computing Engineering

fzpeng@egr.msu.edu

\section{DONG-WOOK YOO, Guest Editor}

Korea Electrotechnology Research Institute Power Conversion \& Control Research Center dwyoo@keri.re.kr

\section{SEUNG-KI SUL, Editor-in-Chief}

Seoul National University

Department of Electrical and Computer Engineering sulsk@plaza.snu.ac.kr 


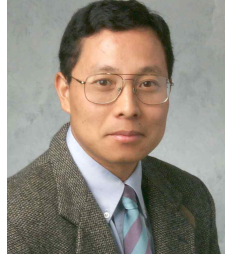

Fang Zheng Peng (M'92-SM'96-F'05) received the B.S. degree in electrical engineering from Wuhan University, China, in 1983 and the M.S. and Ph.D. Degrees in electrical engineering from Nagaoka University of Technology, Japan, in 1987 and 1990, respectively. From 1990 to 1992 , he was a Research Scientist with Toyo Electric Manufacturing Company, Ltd., Toyo, Japan, where he was engaged in the research and development of active power filters, flexible ac transmission system (FACTS) applications, and motor drives. From 1992 to 1994, he was with the Tokyo Institute of Technology, Tokyo, Japan, as a Research Assistant Professor, where he initiated a multilevel inverter program for FACTS applications and a speed-sensorless vector control project. From 1994 to 1997, he was a Research Assistant Professor with the University of Tennessee, Knoxville, TN, USA From 1994 to 2000, he was with the Oak Ridge National Laboratory, where from 1997 to 2000, he was the Lead (Principal) Scientist with the Power Electronics and Electric Machinery Research Center. Since 2000, he has been with Michigan State University, East Lansing, where he is currently a University Distinguished Professor with the Department of Electrical and Computer Engineering. He is the holder of more than 15 patents. Dr. Peng received many awards including the IEEE/IAS IPCSD 2013 Gerald Kliman Innovator Award, the 2009 Best Paper Award in the IEEE Transactions on Power Electronics, the 2011, 2010, 1996 and 1995 Prize Paper Award of Industrial Power Converter Committee in IEEE/IAS; the 1996 Advanced Technology Award of the Inventors Clubs of America, Inc., the International Hall of Fame; the 1991 First Prize Paper Award in IEEE Transactions On Industry Applications; and the 1990 Best Paper Award in the Transactions of the IEE of Japan, the Promotion Award of Electrical Academy. He was an IEEE TAB Awards and Recognition Committee (TABARC) member and has served the IEEE Power Electronics Society in many capacities: Chair of Technical Committee for Rectifiers and Inverters an Associate Editor for the IEEE Power Electronics Transactions, Region 1-6 Liaison, Member-at-Large, Awards Chair, and Fellow Evaluation Committee member.

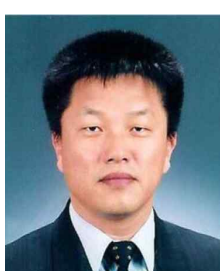

Dong-Wook Yoo received the B.S. degree in electrical engineering from Sung-Kyun-Kwan University (SKKU), Suwon, Korea, in 1983, the M.S. degree in electrical engineering from Yon-Sei University, Seoul, Korea, in 1985, and the $\mathrm{Ph}$ D. degree, majoring in power electronics, from SKKU in 1997. Since 1985, he has been with Korea Electrotechnology Research Institute (KERI), Changwon, Korea, where he is currently an executive director of HVDC Research Division. He is the author or coauthor of more than 30 publications in IEEE Trans., and the holder of more than 60 Korean patents, including 6 U.S. patents. Dr. Yoo is a member of the IEEE PELS and IEEE IAS and the Korean Institute of Power Electronics (KIPE) and the Korean Institute of Electrical Engineers (KIEE). Since 1999, he has been a committee of KIPE, from 2009 to 2010, a committee of KIEE, from 2005 to 2006 and 2009 , served as the chairman of KIPE conference, and the vice president of KIPE in 2010 2011. He was the co-recipient of the 2002 IEEE IECON Best Paper Award, the 2007 ICPE Best Paper Award, Daegu, Korea, the 2011 KIPE JPE Best Paper Award, and the 2013 KERI Grand Award.

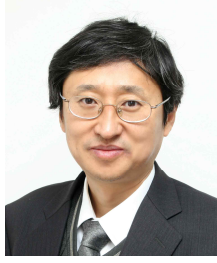

Seung-Ki Sul received his B.S., M.S., and $\mathrm{Ph} . \mathrm{D}$. degrees in Electrical Engineering from Seoul National University, Seoul, Korea, in 1980, 1983, and 1986, respectively. From 1986 to 1988, he was an Associate Researcher in the Department of Electrical and Computer Engineering, University of Wisconsin-Madison, Madison, WI, U.S.A. From 1988 to 1990, he was a Principal Research Engineer with Gold-Star Industrial Systems Co., Korea. Since 1991, he has been a member of the faculty in the School of Electrical Engineering, Seoul National University, where he is currently a Full Professor. Since 2000, he has been an IEEE Fellow. From 2003 to 2004, he was a Research Director and an Acting Consultant for Yaskawa Electric Co., Japan. From 2005 to 2007, he was the Vice Dean of the Engineering College of Seoul National University. In addition, from 2008 to 2011, he was the President of the Electrical Engineering Science Research Institute funded by the Korean Government. He has published over 120 reviewed journal papers, mainly IEEE transactions. He was Technical Chair of the IEEE PESC2006 conference and General Chair of the IEEE ECCE-Asia 2011. He is currently Editor-in-Chief of the Journal of Power Electronics, which is a SCIE registered journal, published by the Korean Power Electronics Institute, Seoul, Korea. His current research interests include power electronic control of electrical machines, electric/hybrid vehicle and ship drives, and power-converter circuits for renewal energy sources. 